\title{
Pengaruh Kebahagiaan dan Manajemen Stres terhadap Kinerja Perawat Rawat Inap (Studi Kasus di RSUD dr. Djasamen Saragih Pematangsiantar, Sumatera Utara)
}

\section{The Effect of Happiness and Stress Management on Inpatient Nurse Performance (Case study: RSUD dr. Djasamen Saragih Pematang Siantar, North Sumatera)}

\author{
Sari Yunita Sidabalok ${ }^{\text {a, }}$, Andita Sayekti ${ }^{\text {b, 2* }}$ \\ a, b Departemen Manajemen, Fakultas Ekonomi dan Manajemen, Institut Pertanian Bogor, Indonesia \\ ${ }^{1}$ sari4696@gmail.com; ${ }^{2}$ anditasayekti@apps.ipb.ac.id* \\ *korespondensi penulis
}

\begin{tabular}{l}
\hline Informasi artikel \\
\hline Kata kunci: \\
Kebahagiaan \\
Kinerja \\
Manajemen stres \\
Perawat \\
Regresi berganda
\end{tabular}

Keywords:

Happiness

Multiple regression

Nurse

Performance

Stress management

\begin{abstract}
ABSTRAK
Kesehatan merupakan faktor penting dalam kehidupan. Salah satu dari tenaga medis yang bertanggung jawab memberikan pelayanan kesehatan adalah perawat. Perawat memiliki peran yang sangat penting dalam membantu proses pelayanan medis di rumah sakit. Penelitian ini bertujuan untuk menganalisis kebahagiaan dan stres kerja perawat dengan mengidentifikasi faktor-faktor yang memengaruhinya. Data yang digunakan dalam penelitian ini melibatkan 72 responden perawat di rawat inap. Metode analisis yang digunakan adalah uji validitas, uji reliabilitas, analisis deskriptif, uji Chi-Square dan analisis regresi berganda menggunakan Statistic Product and Service Solution (SPSS) versi 22.0. Hasil penelitian menunjukkan bahwa kebahagiaan berpengaruh signifikan dan memiliki hubungan positif dengan kinerja. Sedangkan manajemen stres memiliki hubungan positif namun tidak berpengaruh signifikan dengan kinerja. Dapat disimpulkan bahwa perawat di RSUD dr. Djasamen Saragih ratarata memiliki kebahagiaan yang tinggi dan stres kerja yang rendah.
\end{abstract}

\section{ABSTRACT}

Health is an important factor in life. One of the medical personnel who is responsible for providing health services is a nurse. Nurses have a very important role in helping the process of medical services in the hospital. This study aims to analyze happiness at work and job stress of nurses by identifying the factors that influence it. The data used in this study involved 72 inpatient nurses. The analysis method used is validity test, reliability test, descriptive analysis, Chi-Square test, and multiple regression analysis using Statistic Product and Service Solution (SPSS). version 22.0. The results showed that happiness had a significant effect and had a positive relationship with performance. Meanwhile, stress management has a positive relationship but it does not have a significant effect on performance. It can be concluded that the nurse at RSUD dr. Djasamen Saragih, on average, has high happiness and low work stress. 


\section{Pendahuluan}

Setiap organisasi mempunyai visi dan misi yang ingin dicapai. Visi organisasi akan sulit tercapai apabila kinerja secara operasional dan manajerial tidak dapat dijalankan dengan baik. Organisasi memiliki tanggung jawab untuk menciptakan lingkungan kerja yang kondusif untuk para karyawannya. Organisasi baik yang bergerak dalam bidang profit dan non profit memerlukan pengelolaan karyawan agar tercipta keseimbangan antara kebutuhan pegawai dengan visi organisasi tersebut. Karyawan merupakan aset berharga dalam setiap organisasi yang harus dikelola dengan baik sehingga pencapaian visi akan dapat tercapai (Setyawan, 2018). Kinerja yang baik yaitu dapat melakukan pekerjaan sesuai dengan hasil yang ingin dicapai berdasarkan tujuan strategis organisasinya (Iskandar, 2018).

\section{Gambar 1. World Happiness Report 2018}

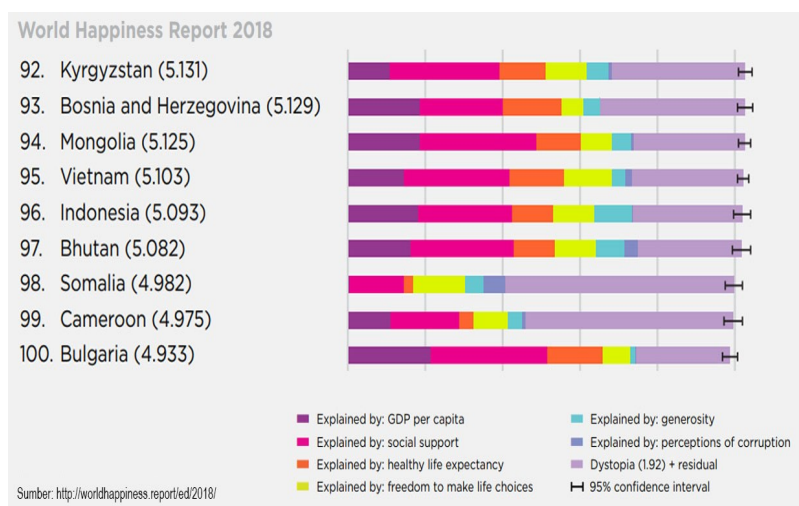

Sumber: (Helliwell et al., 2018)
World Happiness Report pada Gambar

1 merupakan suatu survei kebahagiaan dunia yang bertujuan sebagai acuan pembangunan berkelanjutan. World Happiness Report mengulas pemahaman ilmiah tentang pengukuran dan penjelasan tentang kesejahteraan subjektif. Dalam menentukan kebahagiaan di setiap negara, terdapat beberapa indikator penting yang digunakan. Indikator tersebut adalah pendapatan, dukungan sosial, harapan hidup sehat, kepercayaan, generosity dan kebebasan memilih keputusan. Indikator ini dipercaya dapat memengaruhi kebahagiaan negara secara internasional. Tabel 1 berikut menjelaskan rataan indikator kebahagiaan menurut World Happiness Report.

Tabel 1. Indikator Kebahagiaan World Happiness Report 2018

\begin{tabular}{|c|c|c|c|c|c|}
\hline Variabel & Mean & $\begin{array}{l}\text { Std. } \\
\text { Dev }\end{array}$ & Min & Max & $\mathrm{N}$ \\
\hline Life Ladder & 5.43 & 1.12 & 2.66 & 7.79 & 426 \\
\hline Positive affect & 0.71 & 0.1 & 0.37 & 0.92 & 424 \\
\hline Negative affect & 0.29 & 0.09 & 0.1 & 0.64 & 424 \\
\hline Pendapatan & 9.30 & 1.2 & 6.47 & 11.69 & 412 \\
\hline Dukungan sosial & 0.81 & 0.12 & 0.29 & 0.99 & 424 \\
\hline $\begin{array}{l}\text { Harapan hidup } \\
\text { sehat }\end{array}$ & 63.17 & 7.67 & 43.59 & 76.54 & 424 \\
\hline $\begin{array}{l}\text { Kebebasan } \\
\text { memilih } \\
\text { keputusan }\end{array}$ & 0.76 & 0.13 & 0.3 & 0.99 & 420 \\
\hline Generosity & 0 & 0.16 & -0.3 & 0.67 & 409 \\
\hline Kepercayaan & 0.74 & 0.19 & 0.05 & 0.97 & 393 \\
\hline
\end{tabular}

Life ladder atau kesejahteraan subjektif adalah skor kebahagiaan yang digunakan untuk menentukan tingkat kebahagiaan. Pada 
penelitian yang telah dilakukan responden Timur, Papua Barat dan Sumatra Utara diminta untuk mengurutkan dari tangga 1 adalah provinsi yang paling tidak bahagia di sampai 10 hal hal yang membuat mereka Indonesia (Pierewan \& Veenhoven, 2018). merasa bahagia. Pada Tabel 1 rata-rata skor Dari indikator kebahagiaan, dukungan sosial kebahagiaan adalah 5.43. Skor kebahagiaan merupakan indikator yang paling tinggi. terendah adalah 2.66 dan skor kebahagiaan Harapan hidup sehat, kebebasan memilih tertinggi adalah 7.79. Negara yang memiliki skor terendah adalah Burundi. Finlandia sebagai negara yang memiliki skor kebahagiaan tertinggi. Hal ini disebabkan karena tingkat korupsi yang rendah, perekonomian yang stabil, kebebasan yang tinggi untuk mengambil keputusan serta progresif sosial yang baik. Bukti dari keunggulan Finlandia yang menyebabkan negara ini pantas menjadi negara paling bahagia di dunia adalah sistem peradilan yang dinilai paling independen di dunia, aparat kepolisiannya yang paling terpercaya, kinerja bank yang sangat baik dan penerapan etis kerja yang dijunjung tinggi. Indikator yang memiliki nilai yang paling tinggi adalah harapan hidup sehat. Hal ini memiliki arti bahwa setiap negara menyadari pentingnya kesehatan dalam kehidupan yang bahagia.

Indonesia menduduki peringkat 96 dari 156 negara yang bahwa masyarakat Indonesia memiliki permasalahan dalam mencapai kebahagiaan. Kalimantan Utara, Kalimantan Timur, Gorontalo, Sulawesi Utara dan Maluku Utara adalah provinsi yang paling bahagia di Indonesia. Sementara itu, penduduk provinsi Nusa Tenggara keputusan dan generosity merupakan indikator kebahagiaan rendah di Indonesia. Nilai indikator kebahagiaan yang tinggi terdapat pada indikator dukungan sosial dan pendapatan.

Fenomena menarik menyatakan fakta di lapangan bahwa banyak karyawan melihat pekerjaan sebagai setumpuk tugas dan kewajiban bukan sebagai sesuatu yang mencerahkan apalagi membahagiakan. Hal tersebut dialami oleh sebagian besar perusahaan, dan kondisi ini menjadi penyebab mengapa karyawan tidak dapat mengeluarkan pengabdian dalam bekerja sehingga berdampak pada kinerja yang belum optimal (Wijayanto, 2017).

Karyawan merasa bahagia ketika mereka mempercayai orang- orang tempat mereka bekerja, karyawan merasa bahagia ketika apa yang mereka kerjakan membuat mereka bangga, dan karyawan bahagia saat orang-orang yang bekerja dengan mereka membuat mereka merasa nyaman (Fisher, 2010).

Terdapat faktor yang berasal dari dalam diri maupun dari luar diri karyawan yang dapat membuat karyawan merasa 
bahagia saat bekerja (Pryce-Jones, 2010). advokat, konsultan, komunikator, dan Faktor yang berasal dari dalam diri seperti kesesuaian antara harapan pekerjaan dengan kemampuan diri atau kepribadian individu sedangkan faktor yang berasal dari luar yaitu beban kerja yang tinggi dan lingkungan kerjan yang tidak nyaman (Chinanti \& Siswati, 2018). Perilaku kepemimpinan, karakteristik individu, kepercayaan organisasional, budaya organisasi, dan kepuasan kerja merupakan faktor determinan kebahagiaan (Matheos, 2017).

Kebahagiaan memiliki pengaruh signifikan terhadap kesehatan (Pierewan \& Tampubolon, 2015). Kebahagiaan dan kesehatan cenderung identik, dan karenanya berjalan secara bersamaan. Individu yang sehat akan merasa lebih positif dalam beraktivitas dan mempunyai kebahagiaan yang lebih baik. Kesehatan merupakan salah satu indikator dalam kebahagiaan dunia. Kemudahan dalam mengakses kesejahteraan sosial seperti layanan kesehatan akan meningkatkan kebahagiaan.

Saat memberikan layanan kesehatan, petugas medis (dokter dan perawat) harus dapat bekerja dalam situasi apapun. Perawat memiliki peran yang sangat penting dalam proses medis dalam rumah sakit. Setiap harinya, para perawat bekerja selama 24 jam untuk menjaga dan merawat pasien. Seorang perawat yang profesional berperan sebagai pemberi asuhan keperawatan, pendidik, manajer (Juwita et al., 2018).

Di Inggris, terdapat fenomena bahwa para perawat dapat merasa sangat terbeban oleh pekerjaan mereka sehingga jatuh sakit dan harus mengambil cuti selama rata-rata 51 hari per tahun (Kirk, 2015). Hal ini tentunya akan memengaruhi kinerja rumah sakit dalam pemberian fasilitas kesehatan. Pekerjaan perawat mempunyai tuntutan kerja yang tinggi, seperti jadwal kerja yang padat, tanggung jawab atas keselamatan dan kesehatan orang lain maupun diri sendiri, dan harus dapat bekerja dalam tim (Asi, 2013). Kompleksnya tuntutan pekerjan dan tanggung jawab menjadikan profesi perawat menjadi rentan akan stres kerja bahkan burnout. Jika stres hebat, terus menerus, dan berulang, itu menjadi fenomena negatif atau "distress," yang dapat menyebabkan penyakit fisik dan gangguan psikologis (Gulavani \& Shinde, 2014).

Perawat harus memenuhi standar kebutuhan dalam bekerja. Standar kebutuhan tersebut terdiri dari 2 (dua) hal. Pertama memenuhi standar dalam arti kuantitasnya atau jumlah perawat yang dibutuhkan sesuai dengan kapasitasnya. Terlaksananya tugas seorang perawat dengan baik harus didukung dengan tepat guna dalam menangani sejumlah kasus yang ada di tempat atau bagian tersebut. Standar yang kedua yaitu memenuhi kualitasnya (qualified), artinya mutu kerja dari perawat tersebut benar-benar 
dapat dihandalkan dalam menangani

berbagai kasus yang terjadi di tempat tugas (Fauzan, 2017).

RSUD dr. Djasamen Saragih Kota Pematangsiantar merupakan rumah sakit yang tergolong dalam Badan Layanan Umum Daerah (BLUD) sejak tahun 2014. Rumah sakit ini memiliki 16 unit/instalasi pelaksana fungsional pelayanan yang terdiri dari Instalasi Rawat Jalan, Gawat Darurat, Rawat Inap, Bedah Sentral, Farmasi, Radiologi, Rehabilitasi Medis, Perawatan Intensif, Gizi, Patalogi Klinik, Patologi Anatomi, Pemeliharaan Sarana Rumah Sakit, Sanitasi, Pemulasaraan Jenazah, Haemodialisa, dan Unit Tranfusi Darah Rumah Sakit Jumlah kunjungan pasien RSUD dr. Djasamen Saragih Pematangsiantar mengalami penurunan setiap tahunnya. Jumlah kunjungan pasien pada 3 instalasi rumah sakit dapat dilihat pada Gambar 2.

Gambar 2. Jumlah Kunjungan Pasien 20162018

\begin{tabular}{|c|c|c|c|}
\hline \multirow{6}{*}{$\begin{array}{r}50000 \\
40000 \\
30000 \\
20000 \\
10000 \\
0\end{array}$} & \multirow{2}{*}{\multicolumn{3}{|c|}{$\Delta$}} \\
\hline & & & \\
\hline & & & \\
\hline & & & \\
\hline & & & \\
\hline & 2016 & 2017 & 2018 \\
\hline$\leadsto$ Rawat Inap & 4248 & 3894 & 3021 \\
\hline $\begin{array}{r}- \text { Gawat } \\
\text { Darurat }\end{array}$ & 5683 & 5198 & 4618 \\
\hline $\begin{array}{c}\text { - Rawat } \\
\text { Jalan }\end{array}$ & 44681 & 45076 & 39809 \\
\hline
\end{tabular}

Sumber : Profil RSUD dr. Djasamen Saragih Kota Pematangsiantar 2018
Gambar 2 menunjukkan jumlah kunjungan pasien di unit rawat jalan, rawat inap dan IGD pada tahun 2016-2018. Pada tahun 2018 terdapat penurunan pasien yang terjadi di beberapa instalasi RSUD dr. Djasamen Saragih. Di antaranya adalah instalasi rawat jalan, rawat inap dan juga gawat darurat. Dibanding ketiga instalasi, rawat inap memiliki persentase penurunan pasien yang paling besar yaitu sebesar $22.41 \%$. Sedangkan rawat jalan dan IGD memiliki persentase penurunan sebesar $11.6 \%$ dan $11.5 \%$.

Rumusan masalah dalam penelitian ini adalah (1) Bagaimana persepsi kebahagiaan, stres dan kinerja pada perawat di ruang inap RSUD dr. Djasamen Saragih Kota Pematangsiantar? (2) Bagaimana pengaruh antara kebahagiaan, stres dan kinerja perawat di ruang inap RSUD dr. Djasamen Saragih Kota Pematangsiantar? Penelitian ini bertujuan untuk (1) Mengidentifikasi persepsi kebahagiaan, stres dan kinerja perawat di ruang inap RSUD dr. Djasamen Saragih Kota Pematangsiantar. Menganalisis pengaruh antara kebahagiaan dan stres kerja terhadap kinerja perawat di ruang inap RSUD dr. Djasamen Saragih Kota Pematangsiantar.

\section{Metode}

Sumber daya manusia (perawat) merupakan aset berharga yang harus 
dilindungi oleh organisasi agar dapat atau anggota populasi untuk dipilih menjadi mencapai visinya. Faktor yang memengaruhi kebahagiaan dan stres kerja dikaji melalui kuesioner yang diberikan kepada perawat. Hubungan karakteristik perawat dianalisis dengan menggunakan uji chi-square untuk mengetahui keterikatan dengan kebahagiaan, stres kerja dan kinerja. Kemudian faktor kebahagiaan, stres kerja dan kinerja dianalisis dengan menggunakan analisis deskriptif dan analisis regresi berganda dengan software Statistic Product and Service Solution (SPSS) versi 22.0 untuk menganalisis pengaruh antar variabel.

Hasil analisis digunakan untuk menyusun pengembangan dan pemeliharaan sumber daya manusia di rumah sakit. Jenis data yang akan digunakan dalam penelitian ini adalah data primer dan data sekunder. Data primer diperoleh melalui kuesioner yang dibagikan ke ruangan rawat inap, wawancara dengan kepala ruangan dan pengamatan langsung di lokasi penelitian. Data sekunder diperoleh melalui data primer yang diolah lebih lanjut, studi literatur terkait sebagai data penunjang yang melengkapi data primer yang diperoleh dari buku, jurnal, profil rumah sakit, serta hasil penelitian sampel (Sugiyono, 2019). Purposive sampling adalah teknik penentuan sampel dengan pertimbangan tertentu. Alasan pemilihan sampel dengan menggunakan purposive sampling adalah karena tidak semua sampel memiliki kriteria yang sesuai dengan yang ditentukan (Sugiyono, 2019).

Data selanjutnya dianalisis untuk mendapatkan hasil sesuai dengan tujuan penelitian. Metode pengolahan dan analisis data yang digunakan adalah uji chi square, analisis deskriptif dan regresi linier berganda. Chi square digunakan untuk melihat pengaruh karakteristik dengan variabel penelitian. Analisis data menggunakan regresi linear berganda untuk melihat pengaruh antar variabel. Namun sebelum melakukan analisis regresi terlebih dahulu data di analisis dengan menggunakan uji asumsi klasik. Uji asumsi klasik adalah persyaratan statistik yang harus dipenuhi sebelum menguji dengan regresi linear berganda. Uji asumsi klasik dilakukan agar model regresi yang dihasilkan tidak bias (Priyatno, 2012). Uji asumsi klasik yang akan digunakan adalah uji normalitas, uji multikolinearitas dan uji heteroskedastisitas. terdahulu yang berkaitan dan relevan untuk digunakan. Penelitian ini menggunakan metode non probability sampling. Nonprobability sampling adalah teknik pengambilan sampel yang tidak memberi peluang/kesempatan sama bagi setiap unsur 


\section{Hasil dan Pembahasan}

Karakteristik responden pada penelitian ini terdiri dari umur, jenis kelamin, pendidikan terakhir, lama bekerja, status perkawinan dan status karyawan termasuk kepala ruangan. Penyebaran kuesioner dilakukan kepada seluruh perawat rawat inap sebanyak 72 orang.

Tabel 2. Karakteristik Responden

\begin{tabular}{|c|c|c|c|}
\hline & $\begin{array}{l}\text { Karakteristik } \\
\text { Responden }\end{array}$ & Jumlah & $\begin{array}{c}\text { Persentase } \\
(\%)\end{array}$ \\
\hline \multicolumn{4}{|l|}{ Jenis } \\
\hline \multirow[t]{2}{*}{ Kelamin } & Laki-laki & 2 & 2,78 \\
\hline & Perempuan & 70 & 97,22 \\
\hline \multicolumn{4}{|l|}{ Rentang } \\
\hline Usia & $20-30$ & 7 & 9,72 \\
\hline \multirow[t]{3}{*}{ (tahun) } & $31-40$ & 27 & 37,50 \\
\hline & $41-50$ & 25 & 34,72 \\
\hline & $>50$ & 13 & 18,06 \\
\hline \multirow[t]{3}{*}{ Pendidikan } & SMA/SPK & 10 & 13,89 \\
\hline & Diploma & 37 & 51,39 \\
\hline & S1 & 25 & 34,72 \\
\hline \multicolumn{4}{|l|}{ Lama } \\
\hline Bekerja & $3-6$ & 6 & 8,33 \\
\hline \multirow[t]{2}{*}{ (tahun) } & $7-10$ & 18 & 25,00 \\
\hline & $>10$ & 48 & 66,67 \\
\hline \multicolumn{4}{|l|}{ Status } \\
\hline \multirow[t]{5}{*}{ Perkawinan } & Menikah & 68 & 94,44 \\
\hline & Tidak & & \\
\hline & Menikah & 3 & 4,17 \\
\hline & Pernah & & \\
\hline & Menikah & 1 & 1,39 \\
\hline \multirow{3}{*}{$\begin{array}{l}\text { Status } \\
\text { Karyawan }\end{array}$} & & & \\
\hline & Tetap & 64 & 88,89 \\
\hline & Kontrak & 8 & 11,11 \\
\hline
\end{tabular}

Sumber : Data diolah (2019)

Tabel 2 menjelaskan bahwa perawat di RSUD dr. Djasamen Saragih mayoritas adalah perempuan, dengan rentang usia 3140 tahun. Pendidikan terakhir mayoritas perawat adalah diploma dengan lama bekerja lebih dari 10 tahun. Status perkawinan mayoritas perawat adalah menikah dan mayoritas merupakan perawat tetap.

Berikut merupakan hasil uji chi square karakteristik perawat dengan kebahagiaan.

Tabel 3. Hasil Uji chi square karakteristik perawat dengan kebahagiaan

\begin{tabular}{llll}
\hline $\begin{array}{l}\text { Karakteristik } \\
\text { Karyawan }\end{array}$ & $\begin{array}{l}\text { Chi Square } \\
\text { Hitung }\left(\mathrm{X}^{2}\right)\end{array}$ & $\begin{array}{l}\text { Chi } \\
\text { Square } \\
\text { Tabel }\left(\mathrm{X}^{2}\right)\end{array}$ & Keterangan \\
\hline Usia & 0.665 & 0.05 & Terima H0 \\
$\begin{array}{l}\text { Jenis Kelamin } \\
\text { Pendidikan }\end{array}$ & 0.099 & 0.05 & Terima H0 \\
$\begin{array}{l}\text { Terakhir } \\
\text { Masa Kerja }\end{array}$ & 0.942 & 0.05 & Terima H0 \\
$\begin{array}{l}\text { Status } \\
\text { Perkawinan }\end{array}$ & $\mathbf{0 . 0 0 7}$ & 0.05 & Terima H0 \\
$\begin{array}{l}\text { Status } \\
\text { Karyawan }\end{array}$ & 0.900 & 0.05 & Tolak H0 \\
\hline Sumber : Data diolah(2019) & & Terima H0 \\
\hline
\end{tabular}

Pada Tabel 3 dapat dilihat bahwa usia, jenis kelamin, pendidikan terakhir, masa kerja dan status karyawan tidak memiliki hubungan dengan kebahagiaan karena memiliki nilai chi square hitung yang lebih besar dari chi square tabel $(0,05)$. Sedangkan status perkawinan memiliki nilai chi square hitung yang lebih kecil dari chi square tabel sehingga dapat disimpulkan bahwa status perkawinan memiliki pengaruh signifikan dengan kebahagiaan dalam bekerja. Ada lima faktor yang membuat seseorang bahagia di tempat kerja yaitu (1) dukungan positif dari rekan kerja dan atasan, (2) prestasi seperti keberhasilan menyelesaikan tugas, kesesuaian pekerjaan, 
dan mengembangkan diri, (3) lingkungan kerja fisik seperti fasilitas, (4) kompensasi seperti gaji dan insentif, (5) kesehatan seperti badan sehat dan rileks (Wulandari \& Widyastuti, 2014).

Hasil analisis karakteristik karyawan dengan kebahagiaan memiliki hasil yang berbeda. Usia, jenis kelamin, pendidikan terakhir, masa kerja dan status karyawan tidak memiliki pengaruh dengan kebahagiaan, namun status pernikahan memiliki pengaruh dengan kebahagiaan. Perawat yang belum menikah dan sudah menikah memiliki pola pikir yang berbeda. Selain itu kebutuhan dan tanggung jawab perawat yang sudah menikah tentunya berbeda dengan belum menikah. Hal ini sesuai dengan penelitian yang menyatakan komitmen pernikahan memengaruhi kebahagiaan (Rachmayani \& Kumala, 2016). Apabila komitmen perkawinan dapat dibangun dengan baik, maka mereka akan merasa nyaman dan lebih bahagia dengan perkawinan serta kestabilan dalam hubungan perkawinan akan terjaga. Hasil penelitian ini juga sesuai dengan hasil penelitian yang menyatakan bahwa status pernikahan memiliki pengaruh terhadap kebahagiaan (Pierewan \& Tampubolon, 2015). Mereka yang telah menikah cenderung lebih bahagia. Namun berbeda dengan mereka yang pernah menikah (cerai hidup), cenderung lebih tidak bahagia dibanding dengan yang memiliki status menikah. Sedangkan hasil uji karakteristik dengan stres menunjukkan hasil yang berbeda.

Tabel 4. Hasil uji c chi square karakteristik perawat dengan stres kerja

\begin{tabular}{lcll}
\hline $\begin{array}{l}\text { Karakteristik } \\
\text { Karyawan }\end{array}$ & $\begin{array}{l}\text { Chi Square } \\
\text { Hitung }\end{array}$ & $\begin{array}{l}\text { Chi Square } \\
\text { Tabel }\end{array}$ & Keterangan \\
\hline $\begin{array}{l}\text { Usia } \\
\text { Jenis Kelamin }\end{array}$ & 0.904 & 0.05 & Terima H0 \\
$\begin{array}{l}\text { Pendidikan } \\
\text { Terakhir }\end{array}$ & $\mathbf{0 . 0 4 7}$ & 0.05 & Terima H0 \\
Masa Kerja & 0.765 & 0.05 & Telak H0 \\
$\begin{array}{l}\text { Status } \\
\begin{array}{l}\text { Perkawinan } \\
\text { Status }\end{array}\end{array}$ & 0.064 & 0.05 & Terima H0 \\
Karyawan & 0.903 & 0.05 & Terima H0 \\
\hline Suber: Datama H0 & & \\
\hline
\end{tabular}

Sumber : Data diolah (2019)

Dari Tabel 4 dapat dilihat hasil perhitungan chi square antara karakteritik perawat dengan stres kerja. Pada nilai chi square tabel $\left(\mathrm{x}^{2}\right)$ pendidikan terakhir mempunyai nilai yang lebih kecil dari signifikansi. Maka dapat disimpulkan bahwa pendidikan terakhir memiliki pengaruh signifikan terhadap stres. Pendidikan menjadi indikator penting sebagai modal manusia terhadap kesejahteraan (Pierewan \& Tampubolon, 2015). Pendidikan memiliki pengaruh terhadap kesejahteraan dan kebahagiaan. Pendidikan dapat menjadi acuan seseorang dalam mengelola stres. Individu dengan tingkat pendidikan yang lebih tinggi akan berekspektasi dan lebih siap untuk tekanan yang lebih besar.

Hasil uji chi square karakteristik dengan kinerja memiliki nilai chi square 
hitung lebih besar dibanding dengan chi suare tabel. Sehingga dapat disimpulkan bahwa karakteristik perawat tidak memiliki pengaruh terhadap kinerja.

Analisis Koefisien Determinasi

Koefisien determinasi bertujuan untuk melihat seberapa besar keragaman variansi variabel independen yang dapat menjelaskan variabel dependen.

Tabel 5. Hasil Uji Koefisien Determinasi

\begin{tabular}{rrrrr}
\hline & & $\mathrm{R}$ & Adjusted & \multicolumn{2}{l}{$\begin{array}{l}\text { Std. Error of } \\
\text { Model }\end{array}$} & $\mathrm{R}$ & Square & $\mathrm{R}$ Square & the Estimate \\
\hline 1 & $.502^{\mathrm{a}}$ & $\mathbf{. 2 5 2}$ & .230 & 1.35983 \\
\hline
\end{tabular}

Sumber: Data Diolah (2019)

Penelitian ini menggunakan 2 variabel independen maka koefisien determinasi dapat dilihat pada kolom $\mathrm{R}$ square sebesar $25,2 \%$. Nilai tersebut dapat diartikan bahwa variabel kinerja dapat dijelaskan sebesar $25.2 \%$ oleh variabel kebahagiaan dan stres kerja. Adapun 74.8\% dari variabel kinerja dijelaskan oleh variabel lain di luar lingkup penelitian.

\section{Uji F}

Uji $\mathrm{F}$ bertujuan untuk melihat pengaruh kebahagiaan dan manajemen stres secara bersama sama terhadap kinerja. Apabila nilai signifikasni lebih kecil dari taraf kepercayaan yaitu 0.05 maka dapat disimpulkan bahwa kebahagiaan dan manajemen memiliki pengaruh terhadap kinerja dan jika lebih dari 0.05 maka tidak berpengaruh.

Tabel 6. Hasil Uji F

\begin{tabular}{|c|c|c|c|c|c|}
\hline Model & $\begin{array}{l}\text { Sum of } \\
\text { Squares }\end{array}$ & df & $\begin{array}{c}\text { Mean } \\
\text { Square }\end{array}$ & $\mathrm{F}$ & Sig. \\
\hline \multicolumn{6}{|l|}{ Regression } \\
\hline & 43.021 & 2 & 21.510 & 11.633 & $.000^{b}$ \\
\hline
\end{tabular}

Pada Tabel 6 dapat dilihat bahwa nilai signifikansi sebesar 0.00 yang lebih kecil dari 0.05 maka variabel independen secara simultan memiliki pengaruh terhadap variabel dependen.

Uji T

Uji $\mathrm{T}$ bertujuan untuk mengetahui apakah variabel bebas secara parsial (sendiri) memengaruhi variabel dependen atau terikat. Berikut merupakan hasil analisis data menggunakan uji $\mathrm{T}$.

Tabel 7 Hasil Uji T

\begin{tabular}{lrrrr}
\hline \multicolumn{5}{c}{$\begin{array}{c}\text { Unstandardized } \\
\text { Coefficients }\end{array}$} \\
Model & \multicolumn{1}{c}{$\begin{array}{c}\text { Std. } \\
\text { B }\end{array}$} & Error & \multicolumn{1}{c}{$\mathrm{t}$} & \multicolumn{1}{c}{ Sig. } \\
\hline 1 (Constant) & 26.582 & 2.562 & 10.377 & .000 \\
KEBAHAGIAAN & .160 & .034 & 4.768 & $\mathbf{. 0 0 0}$ \\
MANAJEMEN & .015 & .022 & .681 & $\mathbf{. 4 9 8}$ \\
STRES & & & &
\end{tabular}

Dari tabel hasil uji $\mathrm{T}$ dapat dilihat bahwa faktor kebahagiaan yaitu memiliki pengaruh signifikan terhadap kinerja secara parsial karena nilai sig sebesar 0.000 dan 
manajemen stres tidak memiliki pengaruh signifikan terhadap kinerja karena nilai signifikansi lebih besar dari taraf kepercayaan yaitu 0.498 .

Berdasarkan perhitungan yang telah dilakukan maka diperoleh persamaan regresi berganda sebagai berikut :

$$
Y=26.582+0.160 X_{1}+0.015 X_{2}
$$

Model regresi linear berganda mempunyai nilai konstanta sebesar 26.582 . Konstanta sebesar 26.582 adalah nilai kinerja perawat. Hal ini menunjukkan bahwa kinerja perawat (Y) akan meningkat signifikan dengan adanya kebahagiaan dan manajemen stres.

Faktor kebahagiaan $\left(\mathrm{X}_{1}\right)$ memengaruhi kinerja perawat (Y) sebesar 0.160 dengan tanda positif. Hal ini memiliki arti bahwa apabila kebahagiaan perawat meningkat maka kinerja akan meningkat sebesar 0.160 dengan asumsi variabel lainnya tetap. Kebahagiaan memiliki hubungan positif dengan pelayanan perawat (Ismirawati, 2018) dan kebahagiaan berpengaruh terhadap kinerja (Anggraini, 2018).

Nilai koefisien dari faktor manajemen stres adalah sebesar 0.015 dengan tanda positif. Hal ini berarti bahwa manajemen stres akan meningkatkan kinerja sebesar 0.015 kali. Namun karena memiliki nilai signifikansi 0.498 di mana nilai ini lebih besar dari 0.05 . maka manajemen stres tidak memiliki pengaruh signifikan terhadap kinerja. Hasil penelitian ini relevan dengan penelitian yang menyatakan bahwa stres kerja tidak memiliki pengaruh terhadap kinerja (Anggreini, 2017).

Hasil penelitian melalui analisis regresi menunjukkan bahwa antara kebahagiaan dan kinerja berpengaruh signifikan dan positif. Jika kebahagiaan perawat semakin tinggi maka kinerja perawat akan meningkat juga. Berdasarkan hasil ini perawat berada dalam tingkat kebahagian yang tinggi. Faktor yang memengaruhi kebahagiaan adalah internal dan eksternal. Secara pribadi, bekerja merawat orang sakit merupakan pekerjaan yang memiliki arti tersendiri dan dianggap merupakan hal yang penting bagi kehidupan perawat. Seiring berjalannya waktu, perawat mulai merasa terbiasa dengan pekerjaan yangtelah dilakukan. Terbiasa juga dengan lingkungan yang ada di ruangan tempat bekerja. Hal ini menyebabkan perawat menjalani pekerjaannya seperti rutinitas biasa. Selain itu, pihak rumah sakit tetap perlu memperhatikan lingkungan kerja perawat di ruang inap. Seperti hubungan antara kepala ruangan dengan perawat pelaksana. hubungan antara perawat pelaksana.

Hasil analisis regresi berganda antara stres kerja memiliki hubungan positif dan tidak pengaruh signifikan. Ketika perawat 
mengalami stres kerja yang bersumber dari diri sendiri maka kinerjanya juga menurun. Hal ini menunjukkan bahwa ketika perawat dalam keadaan stres. perawat akan tetap bekerja sesuai prosedur yang ada. Sumber stres yang sama dapat berpengaruh berbeda pada individu karenanya ada perbedaan tanggapan antar individu (Siswanto, 2007). Perbedaan individu ini termasuk dalam karakteristik perawat. Usia dewasa biasanya lebih mampu mengontrol stres dibanding yang usianya lebih muda. Secara biologis tubuh wanita lebih lentur dibanding pria sehingga toleransinya lebih baik. Berdasarkan karakteristik perawat di ruang inap. rata-rata perawat memiliki usia 30-50 dengan lama bekerja sudah lebih dari 10 tahun. Hal ini dapat menjadi pertimbangan stres kerja yang tidak berpengaruh signifikan dengan kinerja.

Rumah sakit adalah fasilitas pelayanan kesehatan yang dibentuk oleh Pemerintah agar masyarakat dapat berkonsultasi masalah kesehatan. Pihak rumah sakit perlu lebih memperhatikan upaya pemeliharaan agar sumber daya bekerja secara optimal. Selain itu. hubungan yang baik yang terjalin di tempat kerja perlu tetap dipelihara. Karena perawat bekerja koordinasi satu dengan yang lain sehingga hubungan yang baik dan membangun perlu dipertahankan agar perawat nyaman dalam bekerja. Kepala ruangan berperan sebagai mediator dalam bekerja dengan perawat pelaksana. tegas dalam memberikan arahan namun dapat membangun suasana kekeluargaan di ruangan. Hubungan yang baik antar rekan sekerja tidak hanya dapat dilakukan ketika dalam bekerja. Rumah sakit juga perlu lebih memperhatikan fasilitas yang ada di rumah sakit. karena terdapat beberapa peralatan di ruang inap yang sudah mulai usang dan rusak. sehingga perawat dapat lebih mudah dalam menggunakannya. Oleh karena itu peneliti memberikan rekomendasi kepada rumah sakit berupa implikasi manajerial melalui Input-Proses-Output (IPO) yang dapat dilihat pada Gambar 3.

Gambar 3. Implikasi Manajerial

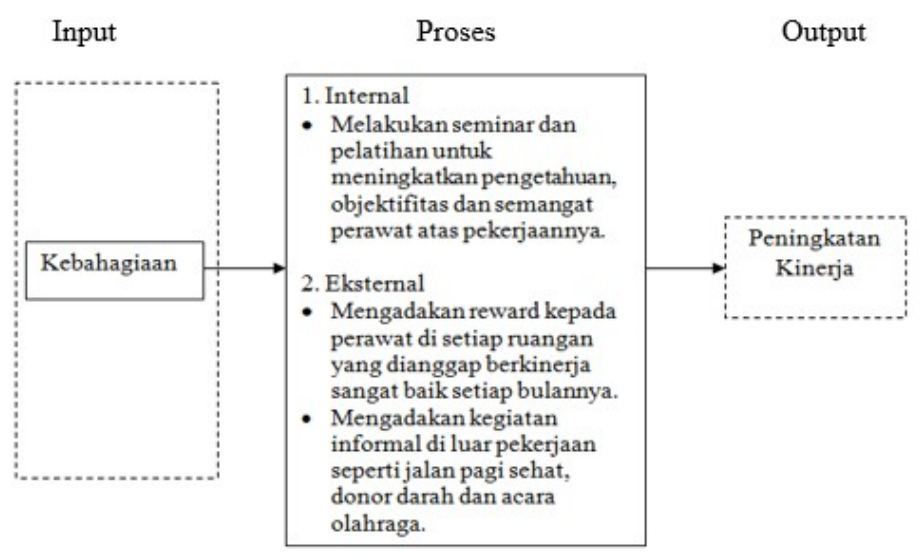

Kegiatan positif yang dirancang oleh rumah sakit dalam rangka memberikan penghargaan terhadap para tenaga medis dapat meningkatkan semangat dan rasa bahagia sehingga dapat meningkatkan kinerja perawat dalam bekerja. 


\section{Simpulan}

Berdasarkan hasil penelitian yang telah dilakukan maka dapat diambil kesimpulan sebagai berikut:

1. Perawat di RSUD dr. Djasamen Saragih rata-rata memiliki kebahagiaan yang tinggi dan stres kerja yang rendah.

2. Secara simultan kebahagiaan dan stres kerja memiliki hubungan yang signifikan. Secara parsial kebahagiaan berpengaruh signifikan dan memiliki hubungan positif dengan kinerja. Hal ini dapat diartikan bahwa ketika kebahagiaan perawat meningkat maka kinerja juga akan meningkat. Sedangkan manajemen stres memiliki hubungan positif namun tidak berpengaruh signifikan dengan kinerja.

\section{Saran}

1. Perawat memiliki objektifitas yang rendah karena telah lama bekerja sebagai perawat. Seminar dan pelatihan perlu diberikan oleh pihak rumah sakit agar dapat meningkatkan objektifitas dalam bekerja agar pengetahuan, skill dan motivasi perawat dapat meningkat. Pihak rumah sakit dapat melakukan program reward di rawat inap. Program tambahan ini dapat membantu perawat menjadi lebih semangat dalam bekerja. seperti memberikan penghargaan terhadap perawat melalui program best nurse melalui penilaian kinerja dan memperhatikan kondisi psikologis perawat. Rumah sakit juga perlu memberikan perhatian lebih terhadap kesehatan perawat. Program seperti jalan pagi sehat, donor darah dan kegiatan olahraga lainnya. Rumah sakit juga sebaiknya melakukan evaluasi secara teratur terhadap kinerja di rumah sakit. Serta melakukan pembaharuan terkait mutu pelayanan ruang inap.

2. Bagi peneliti selanjutnya disarankan untuk melakukan penelitian mengenai variabel lain yaitu budaya organisasi, engagement, motivasi, dan variabel lain untuk kinerja perawat. Selain itu dapat menambahkan persepsi pasien sebagai bahan evaluasi untuk kinerja perawat dengan tujuan memperoleh informasi yang lebih terperinci mengenai kinerja perawat.

\section{Referensi}

Anggraini, R. (2018). Hubungan Kepuasan Kerja Terhadap Kebahagiaan di TempatKerja Pada Karyawan PT Pos Indonesia Pekanbaru. PSYCHOPOLYTAN (Jurnal Psikologi), 2(1), 28-35.

Anggreini, F. (2017). Hubungan Stres Kerja dan Kinerja Karyawan Kantor Perwakilan Jakarta PT Bukit Asam (Persero) Tbk [Skripsi, Institut Pertanian Bogor]. 
https://repository.ipb.ac.id/handle/123 $456789 / 90089$.

Asi, S. P. (2013). Pengaruh Iklim Organisasi dan Burnout terhadap Kinerja Perawat RSUD Dr. Doris Sylvanus Palangka Raya. Jurnal Aplikasi Manajemen, 11(3), 515-523.

Chinanti, D. W. P., \& Siswati, S. (2018). Hubungan Antara Kebahagiaan di Tempat Kerja Dengan Keterikatan Karyawan Pada Karyawan PT. Dwi Prima Sentosa Mojokerto. Jurnal EMPATI, 7(3), 1031-1037.

Fauzan, M. (2017). Pengaruh Stress dan Kepemimpinan terhadap Kinerja Perawat di Rumah Sakit Umum Daerah Pematangsiantar. Jurnal Wawasan Manajemen, 5(1), 89-105.

Fisher, C. D. (2010). Happiness at Work. International Journal of Management Reviews, 12(4), 384-412. https://doi.org/10.1111/j.14682370.2009.00270.x.

Gulavani, A., \& Shinde, M. (2014). International Journal of Science and Research, 3(4). https://www.ijsr.net/search_index_res ults_paperid.php?id=20131598.

Helliwell, J. F., Layard, R., \& Sachs, J. D. (2018). World Happiness Report. Sustainable Development Solutions Network.
Iskandar, D. (2018). Strategi Peningkatan Kinerja Perusahaan Melalui Pengelolaan Sumber Daya Manusia dan Kepuasan Kerja dan Dampaknya Terhadap Kinerja Karyawan. Jurnal Ilmiah Bisnis Dan Ekonomi Asia, 12(1).https://doi.org/10.32812/jibeka. v12i1.8.

Ismirawati, E. (2018). Pengaruh Kebahagiaan dan Budaya Organisasi terhadap Pelayanan perawat di Rumah Sakit Umum Daerah Aji Muhammad Parikesit Tenggarong. Motiva Jurnal Psikologi, 1(1), 59-65.

Juwita, J., Saputra, A., Elisa, E., Theresia, M., \& Suyasa, T. Y. S. (2018). Peran Psychological Detahcment dalam Mengatur Hubungan antara Job Stress dan Well-Being pada Perawat. Jurnal Muara Ilmu Sosial, Humaniora, Dan Seni, $\quad 2(2)$, 481-490. https://doi.org/10.24912/jmishumsen. v2i2.1769.

Kirk, A. (2015). Nurses at breaking point as number off work with stress soars. https://www.theguardian.com/society/ 2015/jan/17/nurses-nhs-stress-leavestaff-breaking-point.

Matheos, M. O. (2017). Faktor-Faktor Determinan Kebahagiaan Kerja Karyawan (Studi Kasus Pada PT. Bank Bukopin Tbk. Cabang Manado. 
Jurnal Riset Bisnis Dan Manajemen, 5(4), 611-630.

Pierewan, A. C., \& Tampubolon, G. (2015). Happiness and Health in Europe: A Multivariate Multilevel Model. Applied Research in Quality of Life, 10(2), 237-252.

https://doi.org/10.1007/s11482-0149309-3.

Pierewan, A. C., \& Veenhoven, R. (2018). Quality of life in provinces in Indonesia; as Measured with Happy Life Years. EHERO Working Papers. https://repub.eur.nl/pub/116016/.

Priyatno, D. (2012). Belajar Cepat Olah Data Statistik dengan SPSS. Yogyakarta: Andi Offset.

Pryce-Jones, J. (2010). Happiness at work: Maximizing your psychological capital for success. Wiley-Blackwell. https://doi.org/10.1002/97804706668 45.

Rachmayani, F., \& Kumala, A. (2016). Pengaruh Perilaku Dominan dan Komitmen Perkawinan terhadap Kebahagiaan Perkawinan pada Istri Bekerja yang memiliki Penghasilan Lebih Tinggi dari Suami. Jurnal Ilmiah Penelitian Psikologi: Kajian Empiris \& Non-Empiris, 2(2), 1-13. https://doi.org/10.22236/JIPP-16.

Setyawan, A. (2018). Analisis Faktor-Faktor yang Mempengaruhi Kinerja
Karyawan (Studi Kasus pada Tiga Perusahaan Fabrikasi Lepas Pantai di Batam dan Karimun). Journal of Accounting and Management Innovation, 2(1), 67-89.

Siswanto, S. (2007). Kesehatan Mental; Konsep. Cakupan. Dan Perkembangannya. Yogyakarta: Andi Offset.

Sugiyono. (2019). Metode Penelitian Kuantitatif, Kualitatif, dan $R \& D-$ MPKK (2nd ed.). Bandung: Alfabeta.

Wijayanto, S. A. (2017). Dampak Iklim Organisasi terhadap Kebahagiaan dan Kinerja Karyawan (Studi pada Universitas Muhammadiyah yogyakarta). Jurnal Bisnis, Manajemen, Dan Akuntansi, 4. http://jurnal.amaypk.ac.id/index.php/j bma/article/view/57.

Wulandari, S., \& Widyastuti, A. (2014). Faktor-Faktor Kebahagiaan Di Tempat Kerja. Jurnal Psikologi, $10(1), 41-52$. 